http://jmscr.igmpublication.org/home/ ISSN (e)-2347-176x ISSN (p) 2455-0450 crossref DOI: https://dx.doi.org/10.18535/jmscr/v8i11.47

\title{
A Comparative Study Between Epidural Plain Ropivacaine and Ropivacaine With Magnesium Sulfate for Elective Lower Limb Surgeries
}

\author{
Authors \\ Rekha P.A.L ${ }^{1^{*}}$, Kalyan Chakravarthy P $^{2}$, Pradeep Kumar Das ${ }^{3}$, Preethi Vaddi ${ }^{4}$ \\ ${ }^{1}$ Postgraduate, Department of Anaesthesiology, GEMS. \\ ${ }^{2}$ Professor \&HOD Department of Anaesthesiology, GEMS. \\ ${ }^{3}$ Assistant Professor, Department of Anaesthesiology, GEMS. \\ ${ }^{4}$ Senior resident, GEMS \\ *Corresponding Author
}

Rekha P.A.L.

Postgraduate, Department of Anaesthesiology, GEMS

\begin{abstract}
Although epidural anesthesia provides adequate anesthesia, it does not allay apprehension induced by fear of surgery and the alien environment of the operation theatre. Many adjuvants like opioids, ketamine, and $\alpha 2$ agonist have been studied as additives to local anesthetics in epidural anesthesia, each having its pharmacology profile and its side effects. The main aim of postoperative analgesia is to provide subjective comfort and inhibit nociceptive impulse caused by surgical trauma, and to blunt somatic and autonomic reflexes in response to pain. We compared the efficacy of plain ropivacaine vs. ropivacaine with magnesium sulfate on time of onset of sensory,motor block, and duration of analgesia.

Method: 60 patients undergoing elective lower limb surgeries were randomized into two groups. One group receives $16 \mathrm{ml}$ of $0.75 \%$ ropivacaine; another group receives $16 \mathrm{ml}$ of $0.75 \%$ Ropivacaine with $1 \mathrm{ml}$ of magnesium sulfate. Each patient was assessed the time of onset of sensory block, motor block, and duration of analgesia.
\end{abstract}

Results: Time of onset of sensory and motor block was statistically significant, whereas no significant difference is seen in the duration of analgesia.

Conclusion: Epidural magnesium $50 \mathrm{mg}$ with $0.75 \%$ ropivacaine for lower limb surgeries shortens the onset of sensory and motor blockade with hemodynamic stability. There is no effect in prolonging the duration of analgesia. No significant adverse effects were seen.

Keywords: Epidural, ropivacaine, magnesium sulfate, sensory, and motor block.

\section{Introduction}

Epidural anesthesia is a technique used for providing both anesthesia and analgesia. It may be combined with other forms of anesthesia. It provides intraoperative hemodynamic stability and reduces perioperative stress response, thus decreasing the complications and improving patient outcomes. It also helps in the early ambulation of the patient by providing relief to postoperative pain and decreasing thromboembolic events. ${ }^{[1]}$

The search for newer and safer anesthetic agents has always been one of the primary needs in anesthesiology practice. Regional anesthesia techniques have seen various modifications over the last two decades with the advent of many newer and safer local anesthetics. ${ }^{[2,3]}$

Ropivacaine is a long-acting amide local anesthetic. It is comparable to bupivacaine in structure, 
pharmacology, and pharmacokinetics but has a lower potential for toxicity. It shows greater selectivity for a sensory blockade and lowers systemic toxicity as compared to bupivacaine. ${ }^{[4]}$

Several studies of magnesium, when administered intravenously or intrathecally, show antinociceptive effects. $^{[5,6,7]}$ Suggested mechanisms underlying these effects include the inhibition of calcium influx and NMDA receptors' antagonism. ${ }^{[8]}$

Not many studies have shown the effects of magnesium when administered intrathecally. ${ }^{[9]}$

The present study is aimed to assess the effect of magnesium as an adjuvant to ropivacaine when administered epidurally on the time of onset of sensory and motor block, duration of analgesia, and associated adverse effects.

\section{Material and Methods}

A prospective randomized comparative study is done after obtaining approval by the hospital ethics committee. Written informed consent was obtained from 60 patients of either sex between 18-60 yrs of age belonging to ASA grade $1 \& 2$ scheduled for elective lower limb surgeries.

The patients were randomized into two groups of 30 each-

Group A (n=30): $0.75 \%$ Ropivacaine $(16 \mathrm{ml})+0.9 \%$ saline $(1 \mathrm{ml})$

Group B (n=30): $0.75 \%$ Ropivacaine $(16 \mathrm{ml})+$ Magnesium sulphate $(1 \mathrm{ml}) 50 \mathrm{mg}$.

The study was conducted for 6 months in the Department of Anaesthesiology, Great Eastern Medical School \& Hospital, Srikakulam.

\section{Inclusion Criteria}

1) Age between 18 to 60 yrs.

2) ASA physical status I or II

3) Bodyweight 50-75kgs (BMI $>18.5$ and $<25)$

4) Patients undergoing elective lower limb surgeries.

\section{Exclusion Criteria}

1) Patient refusal.

2) Patients with a history of cerebrovascular, neurological, cardiovascular, pulmonary, or metabolic disease.
3) Patients in whom central neuraxial blockade is contraindicated.

4) Pregnant and lactating mothers

5) Psychological disorders.

\section{Preoperative Assessment and Premedication}

Every patient underwent a pre-anesthetic check-up a day before surgery, includinga detailed history, complete general physical and systemic examination, and relevant investigations.

All the patients were educated about the 10 points visual analog pain scale (VAPS) at the preoperative visit (0 - no pain, 10 - worst imaginable pain).All patients received adequate fasting orders preoperatively according to the surgery planned.

\section{Study Method}

The patient was shifted to the operating room. $18 \mathrm{G}$ iv cannula was secured.iv fluids were connected. Monitors such as ECG, pulse oximetry, NIBP were connected. Baseline values were noted.

The patients were positioned in the sitting position. Under strict aseptic conditions, the epidural space was identified at the L2-3 or L3-4 space using a loss of resistance to air technique using an 18G Tuohy needle. A $20 \mathrm{G}$ catheter was then advanced into the epidural space for $5 \mathrm{~cm}$. A standard test dose of 2-3 $\mathrm{ml}$ of $2 \%$ lignocaine with adrenaline was given to verify the catheter's correct placement. Then the patient received the appropriate study drug epidurally, slowly over 5 minutes.

Group A $(n=30)$ received $0.75 \%$ Ropivacaine $(16 \mathrm{ml})+0.9 \%$ saline $(1 \mathrm{ml})$

Group B $(\mathrm{n}=30)$ received $0.75 \%$ Ropivacaine $(16 \mathrm{ml})+$ Magnesium sulphate $(1 \mathrm{ml}) 50 \mathrm{mg}$.

The parameters like HR, BP, $\mathrm{SpO} 2$ were monitored. The sensory block was assessed by the pinprick method bilaterally.

The time of onset of motor block was defined as the time to attain a modified Bromage score of $0 .(0:$ no motor block;3:inability to flex ankle joints).

Sensory analgesia was assessed as per VAPS at 2, 3, 4, 5, 6 hours postoperatively. 
Rescue analgesia of $9 \mathrm{ml}$ of $0.25 \%$ ropivacaine was administered to all the patients in the event of pain (VAPS more than 4).

Complications such as hypotension, bradycardia, nausea \& vomiting, respiratory depression, and shivering were also noted.

\section{Results}

\section{Age}

The mean age of Group A was $41.8+/-13.9$ years, and Group B was $35.6+/-12.2$ years. The difference in mean age between the two groups was 6.2 years and was not statistically significant ( $>>0.05)$.

\section{Gender}

The male: female ratio in group B was 23:7 in Group A compared to 26:4 in group B. The sex ratio of the two groups was comparable to each other and statistically non-significant. ( $p>0.05)$.

Table 1:Type of surgery

\begin{tabular}{|l|c|c|}
\hline & Group A & Group B \\
\hline DHS fixation & 6 & 6 \\
\hline ORIF- Femur & 9 & 8 \\
\hline IL nailing Femur/Tibia & 4 & 3 \\
\hline Implant exit - Tibia & 6 & 6 \\
\hline Others & 5 & 8 \\
\hline
\end{tabular}

The type of surgeries between the two groups was compared but was not statistically significant $(\mathrm{p}>0.05)$.

Table 2: Comparison of duration of surgery

\begin{tabular}{|l|c|c|}
\hline Variable & Group A & Group B \\
\hline Duration of surgery & $2.9 \pm 0.56$ & $2.86 \pm 0.41$ \\
\hline
\end{tabular}

The duration of surgery between the two groups wascompared. The mean duration in Group A was $2.90+/-0.56$ hours, and Group B was $2.86+/-0.41$ hours. The difference between the two groups was 0.4 , and it was not statistically significant $(\mathrm{p}>0.05)$.
Table 3: Comparison of time of onset of sensory and motor block in both groups

\begin{tabular}{|l|c|c|c|}
\hline & Group A & Group B & $\mathrm{p}$ value \\
\hline Sensory & $16.9 \pm 3.8$ & $14.6 \pm 3.6$ & $\mathrm{P}<0.05$ \\
\hline Motor & $18.6 \pm 3.8$ & $16.5 \pm 2.6$ & $\mathrm{P}<0.05$ \\
\hline
\end{tabular}

The above table shows the time of onset of sensory and motor block of the two groups A and B. Mean time of onset of sensory block of Group A was $16.9+/-3.8 \mathrm{~min}$. And the same of Group B was $14.6+/-3.6 \mathrm{~min}$ with a difference of mean 2.3 minutes. The result was statistically significant $(\mathrm{p}<0.05)$.

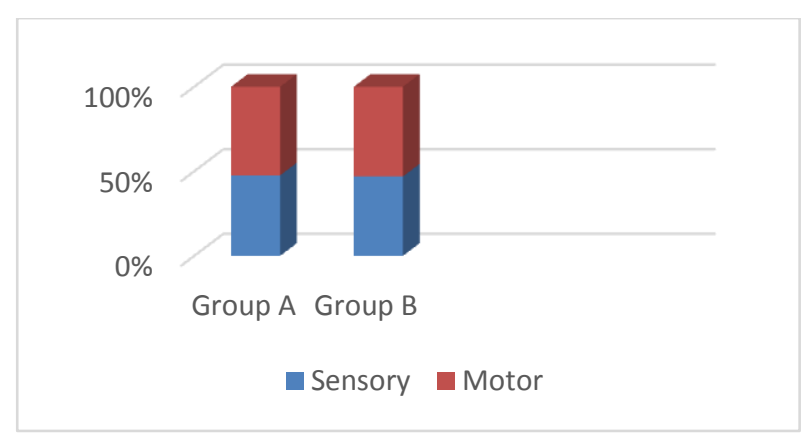

Table 4: Comparison of duration of analgesia between both groups

\begin{tabular}{|l|c|c|c|}
\hline & Group A & Group B & \\
\hline DOA & $3.8 \pm 0.60$ & $4.0 \pm 0.90$ & $\mathrm{p}>0.05$ \\
\hline
\end{tabular}

The mean duration of analgesia of Group A was 3.8 +/- 0.6 hours and that Group B was $4+/-0.9$ hours. The mean difference was 0.2 hours, which was not statistically significant $(\mathrm{p}>0.05)$.

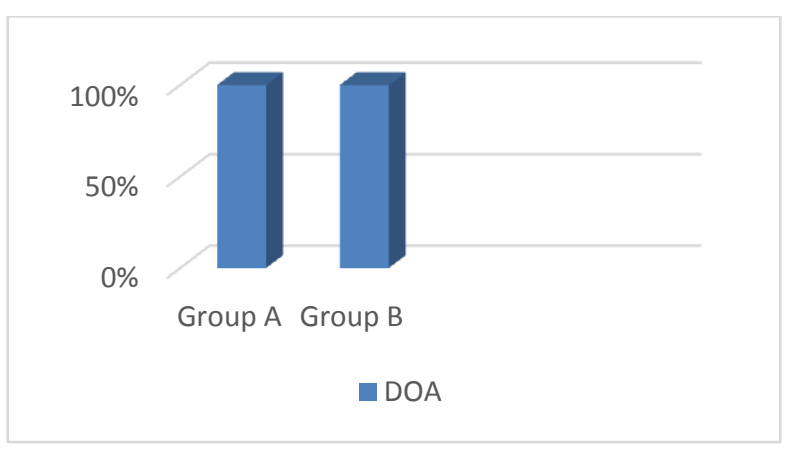


Table 5: Comparison of the intra-operative pulse rate of both groups

\begin{tabular}{|l|c|c|c|}
\hline & Group A & Group B & $\mathrm{p}$ value \\
\hline 5 min & $93.1 \pm 13.0$ & $93.2 \pm 7.5$ & $\mathrm{p}=0.18$ \\
\hline $\mathbf{1 5}$ min & $91.5 \pm 11.5$ & $90.7 \pm 10.3$ & $\mathrm{p}=0.69$ \\
\hline 30 $\mathbf{~ m i n}$ & $87.4 \pm 9.4$ & $91.1 \pm 10.6$ & $\mathrm{p}=0.61$ \\
\hline $\mathbf{4 5}$ min & $86.4 \pm 9.6$ & $81.2 \pm 10.6$ & $\mathrm{p}=0.27$ \\
\hline 60 $\mathbf{~ m i n}$ & $79.4 \pm 10.7$ & $79.4 \pm 11.0$ & $\mathrm{p}=0.38$ \\
\hline EOS & $81.3 \pm 13.8$ & $79.9 \pm 12.0$ & $\mathrm{p}=0.32$ \\
\hline
\end{tabular}

The above table compares the pulse rate of groups intraoperatively at different time intervals of 5, 15, 30, 45, 60 minutes, and end of the surgery, and they were not statistically significant $(\mathrm{p}>0.05)$.

Table 6: Comparison of intra-operative MAP of both groups

\begin{tabular}{|l|c|c|c|}
\hline Time interval & Group A & Group B & $\mathrm{p}$ value \\
\hline $5 \mathrm{~min}$ & $79.1 \pm 9.5$ & $74.6 \pm 9.9$ & $\mathrm{p}=0.32$ \\
\hline $15 \mathrm{~min}$ & $75.9 \pm 9.1$ & $70.5 \pm 9.4$ & $\mathrm{p}=0.48$ \\
\hline $30 \mathrm{~min}$ & $76.5 \pm 7.8$ & $70.2 \pm 9.9$ & $\mathrm{p}=0.32$ \\
\hline $45 \mathrm{~min}$ & $72.6 \pm 7.0$ & $70.9 \pm 8.1$ & $\mathrm{p}=0.53$ \\
\hline $60 \mathrm{~min}$ & $74 \pm 7.6$ & $74 \pm 7.6$ & $\mathrm{p}=0.51$ \\
\hline EOS & 756.9 & 76.87 .7 & $\mathrm{p}=0.30$ \\
\hline
\end{tabular}

The above table compares the mean arterial pressure of groups intraoperatively at different time intervals of $5,15,30,45,60$ minutes, and end of the surgery, and they were not statistically significant $(\mathrm{p}>0.05)$.

Table 7: Postoperative complications

\begin{tabular}{|l|c|c|}
\hline & Group R & Group RM \\
\hline Hypotension & 3 & 2 \\
\hline Bradycardia & Nil & Nil \\
\hline Nausea \& vomiting & Nil & Nil \\
\hline Shivering & Nil & Nil \\
\hline Respiratory depression & Nil & Nil \\
\hline
\end{tabular}

No episode of clinically significant postoperative complications was noted

\section{Discussion}

Regional anesthesia is a safe technique with the advantage of providing surgical anesthesia and prolonged postoperative pain relief. Effective treatment of postoperative pain attenuates autonomic, somatic, and endocrine responses. Research continues concerning different techniques and drugs that could prolong regional anesthesia and postoperative pain relief.
Recently the importance of magnesium in anesthetic practice has been highlighted. Magnesium is an NMDA receptor antagonist, and its antinociceptive effects in animal and human models of pain have been proved. It is beneficial to study supplemental magnesium's role in providing perioperative analgesia because this is a harmless molecule, inexpensive and the biological basis for its potential antinociceptive effect is promising. ${ }^{[5,9]}$

There are studies concerning different routes of magnesium administration, such as intravenous or intrathecally, that improve anesthetic and analgesia quality.

Tanmoy Ghatak et al. ${ }^{[10]}$ investigated the effect of magnesium sulfate $50 \mathrm{mg}$ as an adjunct to $19 \mathrm{ml}$ of $0.5 \%$ bupivacaine epidurally for patients undergoing lower abdominal and lower limb surgeries. They found that the time to achieve the $\mathrm{T} 6$ block was $11.80 \pm 3.21$ minutes in the adjuvant magnesium group and $18.73 \pm 2.79$ minutes in the control group. In the present study, the meantime to achieve the T10 block was $14.6 \pm 3.6$ minutes in the B group, and that of A group was $16.9 \pm 3.8$ minutes.

They also observed that in the magnesium group, no patients suffered from shivering during the study, whereas shivering occurred in four patients belonging to the control group. In the present study, no patients had suffered from shivering in the RM group.

Bajwa et al. ${ }^{[11]}$ compared the effect of epidural ropivacaine and ropivacaine with clonidine combination for elective cesarean section. $20 \mathrm{ml}$ of $0.75 \%$ ropivacaine was the control group, compared with ropivacaine and clonidine 75 micrograms as an adjunct. The onset time of analgesia, sensory, and motor block levels was compared. They concluded that the meantime of onset of sensory block at T6 level and complete motor block was $15.12 \pm 4.36$ minutes and $21.70 \pm 4.20$ minutes, respectively.

In the present study, the onset of T10 and complete motor block was 14.6 \pm 3.6 minutes and 16.9 \pm 3.8 minutes, respectively. The early onset in the control group of their study can be due to pregnancy, which alters the onset and spread of epidural blockade. 
Birbicer et al. ${ }^{[12]}$ investigated the effect of the addition of $50 \mathrm{mg}$ of magnesium sulfate as an adjunct to caudal ropivacaine $0.25 \%$ compared with ropivacaine alone on postoperative analgesic requirements, analgesic duration, and adverse effects. They concluded that the addition of magnesium sulfate as an adjuvant to caudal ropivacaine has no beneficial effect.

In the present study, the duration of analgesia was $3.8 \pm 0.6$ hours and $4 \pm 0.9$ hours in the A group and B group, respectively, which was not statistically significant.

Bilir et al. ${ }^{[13]}$ studied the effect of co-administering $50 \mathrm{mg}$ of magnesium sulfate epidurally as an initial bolus dose followed by a continuous infusion of 100 mg per day with fentanyl for patients undergoing hip surgery. Although the time to the first analgesic requirement was slightly longer when magnesium was co-administered, there was no statistical difference between the two groups (37.1 vs. 51.6 min). No difference between the qualities of sensory or motor block was observed. The cumulative fentanyl consumption in $24 \mathrm{hrs}$ was 437 micrograms in the control group compared to 328 micrograms in the magnesium group.

In the present study, the duration of analgesia was slightly longer in group B as compared to group A, but this was not statistically significant.

In this study, the dose of magnesium used was based on the reference by Buvanendran et al. ${ }^{[14]}$, a rat model in which 188 micrograms of intrathecal magnesium potentiated morphine antinociception. Considering the relative difference between human and rat CSF volume and body weight, the 188 micrograms dose was conservatively extrapolated to $50 \mathrm{mg}$. No neurological findings were reported to be observed in the short term about the intrathecal use of magnesium at this dose in humans.

It is further supported by case reports of Goodman et al. ${ }^{[15]}$ of having inadvertently administered large doses $(8.7 \mathrm{~g}, 9.6 \mathrm{~g})$ of magnesium into epidural space, which did not cause any neurological injury. One limitation of the study was that serum magnesium, and CSF magnesium concentration was not measured. However, it has been studied that most of the total body magnesium (99\%) is intracellular, and the estimation of plasma magnesium does not represent the magnesium content of the body tissues.

Another limitation of our study was a single doseresponse evaluation. Further studies should address different dosages of magnesium with a larger number of patients and different surgical settings.

It is also possible that epidurally administered magnesium is less effective in passing the bloodbrain barrier thanthe intrathecal route and insufficient to achieve the needed CSF concentration.

\section{Conclusion}

Administration of magnesium as an adjuvant to ropivacaine epidurally decreases the latency of central neuraxial blockade in adults without any side effects.

\section{References}

1. Arunkumar S, Hemanth Kumar VR, Krishnaveni N, Ravishankar M, Jaya V, Aruloli M. Comparison of dexmedetomidine clonidine as an adjuvant to ropivacaine for epidural anesthesia in lower abdominal and lower limb surgeries. Saudi J Anaesth 2015; 9:404-8.

2. Mcleod, GA, Burke D. Levobupivacaine. Anaesthesia 2001; 56:331-41.

3. Casati A, Baciarello M. Enantiomeric local anesthetics: can ropivacaine and Levobupivacaine improve our practice Curr Drug Ther 2006;85-9

4. Mcclure.J.H. Ropivacaine British Journal of Anaesthesia 1996; 76: 300- 307.

5. Begon S, Pickering G, Eschalier A, DubrayC. Magnesium increases morphine analgesic effects in different experimental models of pain. Anaesthesiology 2002; 96:627-32.

6. Kroin JS, Mccarthyrj, Von Roenn N, Schwab B, TumanKJ, Ivankovich AD. Magnesium sulfate potentiates morphine antinociception at the spinal level. Anaesthesia Analgesia 2000; 90:913-7. 
7. Susanne Herroeder, Marianne E. Schonherr, Magnesium essentials for the anesthesiologist. Anaesthesiology 2011; 114:971-93.

8. Srivinskas E Laurinaitis R. Use of magnesium in anaesthesiology. Medicine 2002;38:147-50 7)

9. Lysakowsi C, Dumont L, Czarnetzki C, Trame M.R. Magnesium as postoperative adjuvant analgesia: A systematic review of a randomized trial. Anaesthesia Analgesia 2007; 104:1532-9.

10. TanmoyGhatak, Gireesh Chandra, Anita Malik, Dinesh Singh. Evaluation of the effect of Magnesium sulfate vs. clonidine as an adjuvant to epidural bupivacaine. Indian Journal of anesthesia 2010:54:308-13.

11. Sukhminder Jit, Singh Bajwa, Jasbir Kar. Comparison of epidural ropivacaine and ropivacaine clonidine combination for elective cesarean section.Saudi J Anaesthesia .2010;4:48-53

12. H.Birbicer, Davlan. Could adding magnesium as an adjuvant to caudal anesthesia improve postoperative pain control? Paediatric Surgery International 2006;1779:195-198

13. Bilir A, Gulec S, Erkan A, Ozcelik A. Epidural magnesium reduces postoperative analgesic requirement. Br J Anesthesia 2007; 98:519-23.

14. Buvanendran A, McCarthy RJ, Kroin JS, Leong W, Perry P, Tuman KJ. Intrathecal magnesium prolongs fentanyl analgesia: a prospective, randomized controlled trial. Anaesthesiaanalg2002:95:661-7.

15. Goodman EJ, Hass AJ, and Kantor GS: Inadvertent administration of magnesium sulphate through epidural catheter: Report and analysis of a drug error. International $\mathbf{J}$ ObsAnesth 2006:15:63-7.

16. Fazekas T, Schelag BJ, Vos M, Wellens HJ, Lazzara R: Magnesium and the heart: Antiarrhythmic therapy with magnesium. ClinCardiol 1993; 16:768-74. 